\title{
Rsf-1 Influences the Sensitivity of Non- Small Cell Lung Cancer to Paclitaxel by Regulating NF-kB Pathway and Its Downstream Proteins
}

\author{
Xitao Chen ${ }^{a, b, c}$ Xiaodi Sun ${ }^{d}$ Jingqian Guann ${ }^{a, c}$ Junda Gaja,c Jilin Xing ${ }^{a, c} \quad$ Lin Fu ${ }^{a, c}$ \\ Shuli liu ${ }^{a, c}$ Feifei Shen" ${ }^{a, c}$ Keyan Chen ${ }^{\mathrm{e}}$ Wenya Lib Libo Han ${ }^{\mathrm{b}}$ Qingchang Li $\mathrm{Li}^{\mathrm{a}, \mathrm{c}}$ \\ aDepartment of Pathology, College of Basic Medical Sciences, China Medical University, Shenyang; \\ bDepartment of Thoracic Surgery, the First Affiliated Hospital, China Medical University, Shenyang; \\ 'Department of Pathology, the First Affiliated Hospital, China Medical University, Shenyang; \\ 'Department of Geriatrics, the First Affiliated Hospital, China Medical University, Shenyang; \\ eDepartment of Laboratory Animal Science, China Medical University, Shenyang, China
}

\section{Key Words}

Rsf-1 - Non-small cell lung cancer • Paclitaxel $\bullet$ Resistance $\cdot$ NF-kB pathway

\begin{abstract}
Background/Aims: The therapeutic efficacy of paclitaxel is hampered by chemotherapeutic resistance in non-small cell lung cancer (NSCLC). Rsf-1 enhanced paclitaxel resistance via nuclear factor- $\mathrm{KB}$ (NF-KB) in ovarian cancer cells and nasopharyngeal carcinoma. This study assessed the function of Rsf-1 in the modulation of the sensitivity of NSCLC to paclitaxel via the NF-KB pathway. Methods: The mRNA and protein levels of the related genes were quantified by RT-PCR and Western blotting. Rsf-1 silencing was achieved with CRISPR/Cas9 gene editing. Cell cycle, migration and proliferation were tested with flow cytometry, transwell test and CCK8 test. Cell apoptosis was analyzed with flow cytometry and quantification of C-capase3. The parameters of the tumors were measured in $\mathrm{H} 460$ cell xenograft mice. Results: Rsf- 1 was highly expressed in $\mathrm{H} 460$ and $\mathrm{H} 1299$ cells. Rsf- 1 knockout caused cell arrest at the G1 phase, increased cell apoptosis, and decreased migration and cell proliferation. Rsf1 knockout increased the inhibition of cell proliferation, the reduction in cell migration and the augment in cell apoptosis in paclitaxel treated H460 and H1299 cells. Rsf-1 knockout further enhanced the paclitaxel-mediated decrease in the volume and weight of the tumors in $\mathrm{H} 460$ cell xenograft mice. Helenalin and Rsf- 1 knockout decreased the protein levels of $p-P 65$, $\mathrm{BCL} 2, \mathrm{CFLAR}$, and XIAP; hSNF2H knockout decreased the protein level of NF-KB p-P65 without altering Rsf-1 and p65 protein levels, while Rsf-1 and hSNF2H double knockout decreased the
\end{abstract}




\section{Cellular Physiology Cell Physiol Biochem 2017;44:2322-2336 \\ \begin{tabular}{l|l} 
DOI: 10.1159/000486116 & $\begin{array}{l}\text { O 2017 The Author(s). Published by S. Karger AG, Basel } \\
\text { www.karger.com/cpb }\end{array}$
\end{tabular} \\ Chen et al.: Rsf-1 Influences the Sensitivity of Non-Small Cell Lung Cancer to Paclitaxel Drug}

level of NF-KB p-P65, in $\mathrm{H} 1299$ and $\mathrm{H} 460$ cells. Conclusion: These results demonstrate that Rsf- 1 influences the sensitivity of NSCLC to paclitaxel via regulation of the NF-KB pathway and its downstream genes.

(C) 2017 The Author(s)

Published by S. Karger AG, Basel

\section{Introduction}

Lung cancer is the leading cause of cancer-related mortality around the world [1,2]; and non-small cell lung cancer (NSCLC) accounts for $85 \%$ of all lung cancer cases. The overall 5 -year survival rate for stage IIIB/IV NSCLC is 1-5\%, and approximately $70 \%$ of NSCLC patients are diagnosed at an advanced stage with local metastasis [3]. Chemotherapy can prolong the life of patients with advanced non-small cell lung cancer and effectively improve their quality of life [1]. Paclitaxel (PTX), a class of diterpenoid alkaloids, is a plant anticancer drug that shows effective and wider-spectrum anti-tumor activity in vivo and in vitro [4], and is widely used as a first-line chemotherapy regimen in the treatment of malignant tumors, such as breast cancer, non-small cell lung cancer, and ovarian cancer [5]. However, its therapeutic efficacy is restricted by the increasing frequency of chemotherapeutic resistance in NSCLC [6].

A variety of genes have been implicated in the development of primary or secondary resistance to paclitaxel in NSCLC [6]. Rsf-1 (also known as HBXAP) is a gene in the chromosome 11q13.5 locus [7]. Rsf-1 encodes a histone-binding protein named remodeling and spacing factor 1 (Rsf-1), which was found to interact with human sucrose nonfermenting protein 2 homologue (hSNF2H) to form an ISWI chromatin remodeling complex [8], which is involved in chromatin remodeling and transcriptional regulation [9]. Rsf-1 is amplified and/or overexpressed in various cancers, including ovarian [7, 8], breast [10], bladder [11], esophageal [12], lung [13], colon [14], and head and neck cancers [15]. Elevated levels of Rsf-1 are correlated with poor prognosis [16]. Inhibition of Rsf-1 reduces proliferation of cancer cells [8], suggesting an important role for Rsf-1 amplification and/or overexpression in the maintenance of cell survival and growth. It has also been demonstrated that Rsf-1 contributes to paclitaxel resistance by formation of the Rsf-1/hSNF2H complex [17]. Rsf-1 enhanced paclitaxel resistance via nuclear factor- $\kappa \mathrm{B}(\mathrm{NF}-\kappa \mathrm{B})[17,18,19]$, Akt [17] and CREBbinding protein [17] by augmenting the expression of genes necessary for the development of chemoresistance. These genes include those involved in apoptosis (CFLAR, XIAP, BCL2, and BCL2L1) [18], the cell cycle (Survivin) [19] and inflammation (PTGS2) [18] in ovarian cancer cells [17] and nasopharyngeal carcinoma [19].

Overexpressed Rsf-1 contributes to malignant cell growth, invasion and poor overall survival [20] by regulating the NF- $\kappa \mathrm{B}$ pathway activity [13] and the expression of MMP2 [13], bcl-2 [13], p-IкB [13], cyclin D1 [20] and ERK [20] in NSCLC. However, the role of Rsf1 in conferring paclitaxel resistance to NSCLC has not been investigated. In this study, the function of Rsf-1 in the modulation of the sensitivity of NSCLC to paclitaxel was assessed by silencing Rsf- 1 in NSCLC cells and xenograft mice. The involvement of the NF- $\kappa B$ pathway was also tested. Our results demonstrated that Rsf- 1 influenced the sensitivity of NSCLC to paclitaxel via regulation of the NF- $\kappa$ B pathway.

\section{Materials and Methods}

Material

Helenalin (NF- $\kappa$ B inhibitor) was purchased from Santa Cruz Inc. (USA). The female nude mice were provided by Department of Experimental Animals, China Medical University (Shenyang, China).

Cell Culture

Non- small cell lung cancer A549, H1299, H460, and SPC cells, and human bronchial epithelial HBE cells (Institute of Cell Biology, Chinese Academy of Science, Shanghai, China) were cultured in DMEM media 


\section{Cellular Physiology Cell Physiol Biochem 2017;44:2322-2336 \\ \begin{tabular}{l|l|l} 
and Biochemistry Published online: December 15, 2017 & $\begin{array}{l}\text { (c) } 2017 \text { The Author(s). Published by S. Karger AG, Basel } \\
\text { www.karger.com/cpb }\end{array}$
\end{tabular} \\ Chen et al.: Rsf-1 Influences the Sensitivity of Non-Small Cell Lung Cancer to Paclitaxel}

Drug

containing 10\% serum and 1\% PenStrep (100 U/mL Penicilium and $100 \mu \mathrm{g} / \mathrm{mL}$ Streptomycin), at $37^{\circ} \mathrm{C}$ in an incubator containing $5 \% \mathrm{CO}_{2}$.

\section{Transfection}

Transfection of H1299 cells and H460 cells with Rsf-1 CRISPR/Cas9 KO Plasmid (m), hSNF2H CRISPR/ Cas 9 KO Plasmid (h), and Control Plasmid (Santa Cruz Inc. USA) were performed with Lipofectamine 2000 (Invitrogen) according to the manufacturer's instructions. $1 \mathrm{~mL}$ of cell suspension was added to $10 \mathrm{ml}$ of complete media in a culture flask and briefly incubated at $37^{\circ} \mathrm{C}$ in an incubator containing $5 \% \mathrm{CO}_{2}$ for 24 h. Afterwards, the media was replaced with $10 \mathrm{ml}$ Opti-MEM, a mixture containing $25 \mu \mathrm{l}$ of Lenti-Easy Packaging Mix, $60 \mu \mathrm{l}$ Lipofectamine 2000, $2895 \mu \mathrm{l}$ of Opti-MEM, and $20 \mu \mathrm{l}$ of the following: Rsf-1 CRISPR/ Cas9 KO Plasmid, hSNF2H CRISPR/Cas9 KO Plasmid, or Control Plasmid. After the cells were incubated at $37^{\circ} \mathrm{C}$ in an incubator containing $5 \% \mathrm{CO}_{2}$ for $8 \mathrm{~h}$, the media was replaced with $12 \mathrm{ml}$ DMEM containing $10 \%$ serum and cultured at $37^{\circ} \mathrm{C}$ in an incubator containing $5 \% \mathrm{CO}_{2}$ for another $48 \mathrm{~h}$. Cells were harvested and stored at $-80^{\circ} \mathrm{C}$ for further analysis.

\section{Western blotting}

Western blotting was performed according to literature [21] with some modifications. The total protein of the cells was extracted using $500 \mu$ l Lysis Buffer containing $2 \mu \mathrm{l}$ protease inhibitor Mix (Protein extract Kit, Vazyme Inc., USA). The protein concentrations were measured with BCA Protein Assay Kit (Solarbio Inc., Beijing, China) according to the manufacturer's instructions. Proteins were differentiated on polyacrylamide gel and transferred to PVDF membrane (Millipore Co., USA). Membrane was blocked in 5\% skim milk in TBST, incubated with primary antibodies and secondary antibodies in TBST containing skim milk, incubated in ECL (Invitrogen), exposed to X-ray film, and developed. The signals were quantified with a densitometer. The target gene signal was normalized with $\beta$ - actin or GAPDH signal and represented by the ratio of target gene signal to the internal control gene signal.

\section{Real-time RT-PCR}

Total RNA was prepared from the cells using Trizol reagent (DP431, TIANDEN, Beijing, China) according to the manufacturer's instructions. The amount and purity of the RNA were measured with a spectrophotometer. It was taken as pure if the OD260/OD280 was between 1.8 and 2.0. The primers of Rsf- 1 and $\beta$-actin were designed using DNASTAR software based on the mRNA sequence of these genes in GenBank (Table1). The mRNA expression of Rsf- 1 was quantified using the total RNA as a template with One Step SYBR $\AA$ PrimeScript ${ }^{\mathrm{TM}}$ RT-PCR Kit II (Perfect Real Time) (TAKARA, Dalian, China) according to the manufacturer's instructions. $\beta$-actin was used as an internal standard. The relative level of the mRNA expression of Rsf-1 was calculated with $2^{-\Delta \Delta c t}$.

\section{Immunofluorescence (IF) staining}

IF staining was performed according to literature [22]. Cells were fixed in $4 \%$ paraformaldehyde on slides, incubated in $0.5 \%$ Triton X-100/PBS, blocked with goat serum, detected with primary antibody and florescent-labelled secondary antibody, stained with DAPI (Calbiochem, San Diego, USA), mounted, and observed with laser scanning confocal microscopy.

Table 1. Primers used for real-time RT-PCR

Genes GenBank N0. Primers

Forward: 5'-AGGAGGCGCTCTCAAGTGGGCTCCT-3'

Flow cytometry test of cell cycle

RSF-1 NM_016578.3 Reverse: 5'-GATCCGCAGAGGAGCCCACTTGAGA-3'

$10 \mathrm{ml}$ of cell suspension $\left(1-5 \times 10^{6}\right.$ cells $\left./ \mathrm{mL}\right)$ was spun at 500-1000 rpm for $5 \mathrm{~min}$. The cell pellet was washed with PBS once and fixed in $3.70 \%$ ice ethanol at $4{ }^{\circ} \mathrm{C}$ for 2 hours. After

Forward: 5'-GGCACCGCAGGCCCCGGGATGCTAG-3'

GAPDH NM_001256799.2

Reverse: 5'-CTGCGCACTAGCATCCCGGGGCCTG-3' 


\section{Cellular Physiology Cell Physiol Biochem 2017;44:2322-2336 \\ \begin{tabular}{l|l|l}
\hline and Biochemistry 10.1159/000486116 & $\begin{array}{l}\text { C } 2017 \text { The Author(s). Published by S. Karger AG, Basel } \\
\text { www.karger.com/cpb }\end{array}$ \\
\hline
\end{tabular} \\ Chen et al.: Rsf-1 Influences the Sensitivity of Non-Small Cell Lung Cancer to Paclitaxel}

Drug

washing with PBS twice, the cells were suspended in PBS containing $50 \mathrm{mg} / \mathrm{L}$ RNase A and $25 \mu \mathrm{g} / \mathrm{ml} \mathrm{PI} \mathrm{and}$ incubated in dark at $25^{\circ} \mathrm{C}$ for $15 \mathrm{~min}$. The cells at different phases were measured using flow cytometry with an excitation wave length of $488 \mathrm{~nm}$ and an emission wave length greater than $560 \mathrm{~nm}$ to detect PI signal.

\section{Flow cytometry test of apoptosis}

$10 \mathrm{ml}$ of cell suspension $\left(1-5 \times 10^{6}\right.$ cells $\left./ \mathrm{mL}\right)$ was spun at $500-1000 \mathrm{rpm}$ for $5 \mathrm{~min}$. The cell pellet was washed with PBS once and fixed in $70 \%$ ice ethanol at $4{ }^{\circ} \mathrm{C}$ for 2 hours. After the fixation solution was removed, the cells were suspended in $3 \mathrm{ml}$ PBS for $5 \mathrm{~min}$. This was filtered once with a 400 gauge filter and centrifuged at $1000 \mathrm{rpm}$ for $5 \mathrm{~min}$, and then the cell pellet was stained in $1 \mathrm{ml}$ PI staining solution containing $50 \mathrm{mg} / \mathrm{L}$ RNase A and $25 \mu \mathrm{g} / \mathrm{ml} \mathrm{PI}$ at $4{ }^{\circ} \mathrm{C}$ in the dark for $30 \mathrm{~min}$. Both the living and dead cells were measured using flow cytometry with an exciting wave length of $488 \mathrm{~nm}$ and an emission wave length greater than $630 \mathrm{~nm}$.

Transwell test of the invasion capacity of the cells

H460 cells, H1299 cells, transfected H460 cells and transfected H1299 cells were starved in the media without serum for 12 hours, and then they were harvested and washed with PBS twice. The cells were suspended in DMEM containing BSA at a density of $5 \times 10^{5} \mathrm{cells} / \mathrm{ml}$. Cells for all of the four lines were divided into two portions: one portion was not treated and the other portion was added with $4 \mu \mathrm{g} / \mathrm{ml}$ of paclitaxel. $500 \mu \mathrm{l}$ of DMEM containing 20\% FBS was added to the lower chamber of each transwell on a 24 well plate. $200 \mu \mathrm{l}$ of cell suspension was seeded into the upper chambers of the transwells and cultured at $37^{\circ} \mathrm{C}$ in an incubator containing $5 \% \mathrm{CO}_{2}$ for $24 \mathrm{~h}$. The transwell chambers were taken out. After the media in the upper chambers were absorbed, the transwell chambers were moved into wells containing $800 \mu \mathrm{l}$ of methanol, and fixed at room temperature for $30 \mathrm{~min}$. The transwell chambers were taken out again. The solution in the upper chambers was absorbed and the cells on the upper surface of the membrane on the bottom of the upper chamber were removed, and the transwell chambers were moved into wells containing $800 \mu \mathrm{l}$ of crystal violet staining solution and stained at room temperature for 15-30 min. After being rinsed in PBS several times, the transwell chambers were taken out, the solution in the upper chamber was absorbed, and the membrane was lifted and turned over to air dry. After the membrane was transferred to a slide and sealed, it was observed under a microscope and photographed.

\section{CCK8 test of cell proliferation}

Cells were harvested at exponential phase and suspended in DMEM media at $5 \times 10^{5}$ cells $/ \mathrm{ml}$. After $100 \mu \mathrm{l}$ of cell suspension was added to each well and incubated at $37^{\circ} \mathrm{C}$ for 24 hours, paclitaxel was added, and the cells were incubated. $10 \mu$ l CCK8 (CCK8 kit, Dojindo, Japan) was added to each well and incubated for 1-4 hours. The signal was measured at absorption wave lengths of $450-490 \mathrm{~nm}$, and reference wave lengths of $600-650 \mathrm{~nm}$. Each sample was tested as triplicate. Zero control was set with wells containing DMEM media and CCK8, but no treatment reagents.

\section{Test of formation of tumors in nude mice}

The female nude mice (6-week old, body weight 18-20g) were raised under pathogen-free conditions at $23 \pm 2{ }^{\circ} \mathrm{C}$ with $60 \pm 5 \%$ humidity. Animals were divided into four groups: (1) mice transplanted with H460 cells; (2) mice transplanted with H460 cells and treated with paclitaxel; (3) mice transplanted with H460 Rsf-1KO cells; and (4) mice transplanted with H460 Rsf-1KO cells and treated with paclitaxel. Cells in the exponential phase were suspended in complete DMEM media at $2 \times 10^{7}$ cells $/ \mathrm{ml} .0 .1 \mathrm{ml}$ of the cell suspension was injected subcutaneously in the back of the mice. When the tumors became visible, the tumors were measured by the length (L) and width (d) every day. The volumes of the tumors were calculated using the formula $V=0.5 \times \mathrm{L} \times \mathrm{d}^{2}$, and growth curves of the tumors were plotted as the volume of the tumor versus the time. Ten days after the tumors were formed, the mice were injected with paclitaxel at $10 \mathrm{mg} / \mathrm{kg}$ every other day through the tail vein. Thirty days after tumor formation, the mice were sacrificed and the tumors were dissected out and weighed.

\section{Statistical analysis}

All data were collected from the experiments performed in triplicate. Statistical analysis was carried out using the Graphpad Prism 5. Comparison between groups was performed using paired t test. Multiple 


\section{Cellular Physiology Cell Physiol Biochem 2017;44:2322-2336 \\ \begin{tabular}{ll|l} 
and Biochemistry Published online: December 15, 2017 & $\begin{array}{l}\text { C } 2017 \text { The Author(s). Published by S. Karger AG, Basel } \\
\text { www.karger.com/cpb }\end{array}$ \\
\hline
\end{tabular} \\ Chen et al.: Rsf-1 Influences the Sensitivity of Non-Small Cell Lung Cancer to Paclitaxe Drug}

comparisons were performed using one-way repeated measures ANOVA, followed by Bonferroni post hoc test to determine the significance of the differences. Final results were presented as the mean \pm SD. P $<0.05$ was taken as statistically significant.

\section{Results}

\section{Knockout of Rsf-1 in H460 and H1299 cells}

Rsf-1 was highly expressed in H460 and H1299 cells at the protein level (Fig. 1A, B) and the mRNA level (Fig. 1C), and less expressed in A549 and SPC cells. After transfection by the vector Rsf-1 CRISPR/Cas9 KO Plasmid, no Rsf-1 protein was detectable with IF in both $\mathrm{H} 460$ and H1299 cells (Fig. 2B). Western blotting analysis showed that Rsf-1 protein levels dramatically decreased in the transfected H460 and H1299 cells compared with the corresponding control cells (Fig. 2A). These results indicated that Rsf-1 was successfully knocked out in H460 and H1299 cells.

\section{Effect of Rsf-1 knockout in H460 and H1299 cells}

Flow cytometry analysis (Fig. 3A to D) showed that Rsf-1 knockout significantly increased the cells in G1 phase, decreased the cells in S phase, and inhibited the transit from G1 phase to S phase in H460 and H1299 cells ( $\mathrm{p}<0.05$ ). Rsf- 1 knockout significantly increased cell apoptosis ( $\mathrm{p}<0.05$ ) in both H1299 and H460 cells (Fig. 3E to H). Migration analysis showed that the migration ability was significantly decreased in H1299 (Fig. 4A, C, E) and H460 cells (Fig. 4F, H, J) after Rsf-1 was knocked out ( $\mathrm{p}<0.05$ ).

Influence of Rsf-1
knockout on the effect of
paclitaxel in H460 and
H1299 cells
In both H1299 (Fig. 4A
to E) and H460 (Fig. 4F to J), paclitaxel alone and Rsf-1 knockout alone significantly ( $\mathrm{p}<0.001$ ) decreased the cell migration ability; Rsf-1 knockout further significantly

Fig. 1. Expression levels of Rsf1 mRNA and protein in cultured cell lines. Panel A: Rsf-1 protein was detected in the cell lines with Western blotting; panel B: quantitative volume of Rsf-1 protein in the cell lines; panel C: quantitative volume of Rsf-1 mRNA was detected with Real-time RTPCR. HBE, A549, H1299, H460 and SPC represent the corresponding cell lines; $\beta$-actin was used as an internal standard for Western blotting. GAPDH was used as an internal standard for Real-time RT-PCR. Rsf-1 mRNA and protein were highly expressed in cell lines of H1299 and H460.

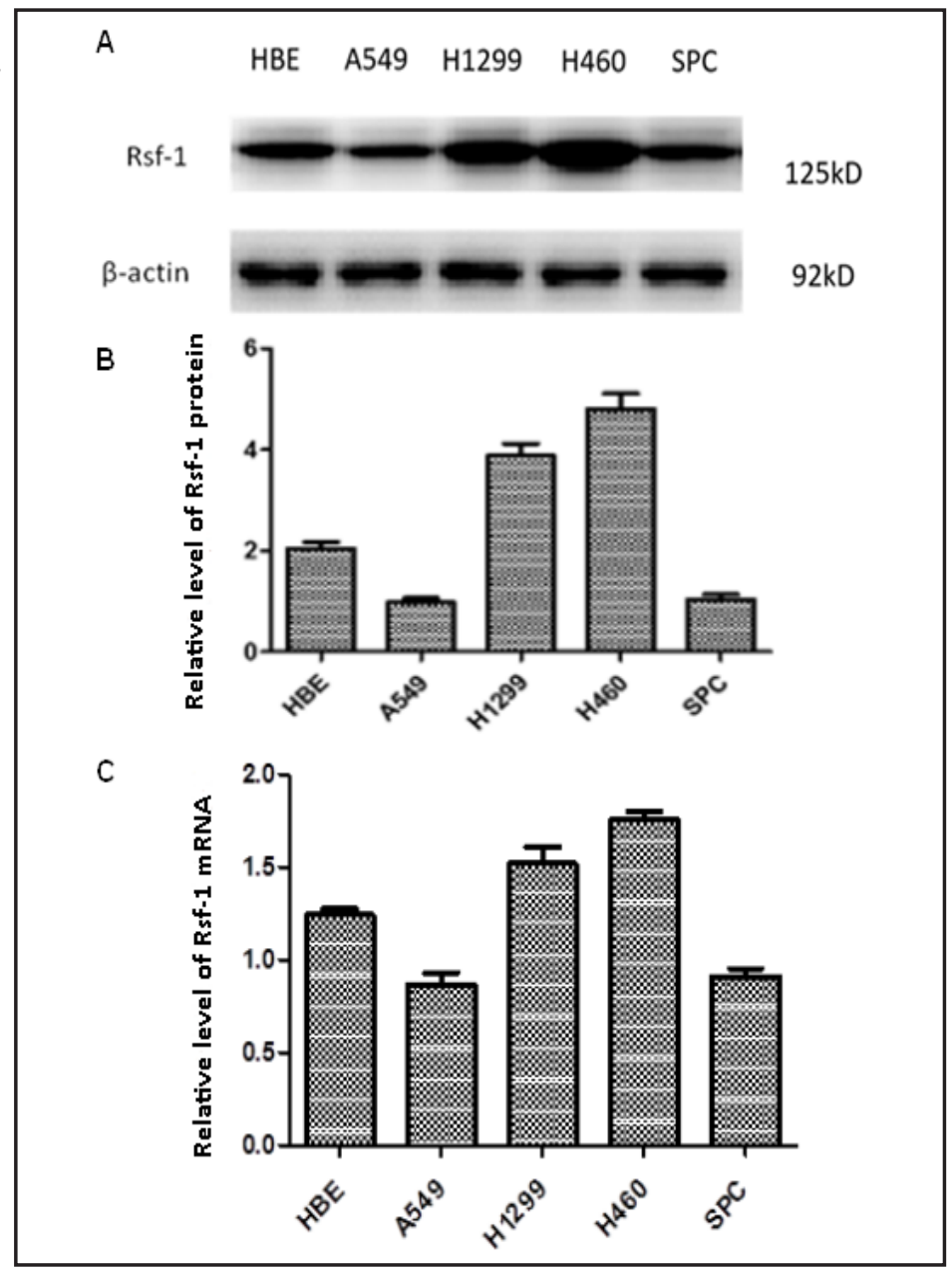


Chen et al.: Rsf-1 Influences the Sensitivity of Non-Small Cell Lung Cancer to Paclitaxel Drug

Fig. 2. Expression of Rsf-1 protein detected in the cells of H1299 and H460 with Rsf1 knockout. Panel A: expression of Rsf-1 protein detected with Western blotting; H1299-CON, control H1299 cells; H1299 Rsf-1KO, H1299 cells with Rsf-1 knocked out; H460-CON, control H460 cells; H460 Rsf-1KO, H460 cells with Rsf-1 knocked out. Most Rsf-1 protein was depleted in H1299 cells with Rsf- 1 knockout and H460 cells with Rsf-1 knockout. $\beta$-actin was used as an internal standard. Panel B: expression of Rsf-1 protein detected with IF; H1299-CON means control H1299 cells; H1299 Rsf-1KO means H1299 cells with Rsf-1 knockout; H460-CON means control H460 cells; H460 Rsf-1KO means H460 cells with Rsf-1 knockout. No Rsf-1 protein was detected in H1299 cells with Rsf-1 knockout and H460 cells with Rsf-1 knockout.

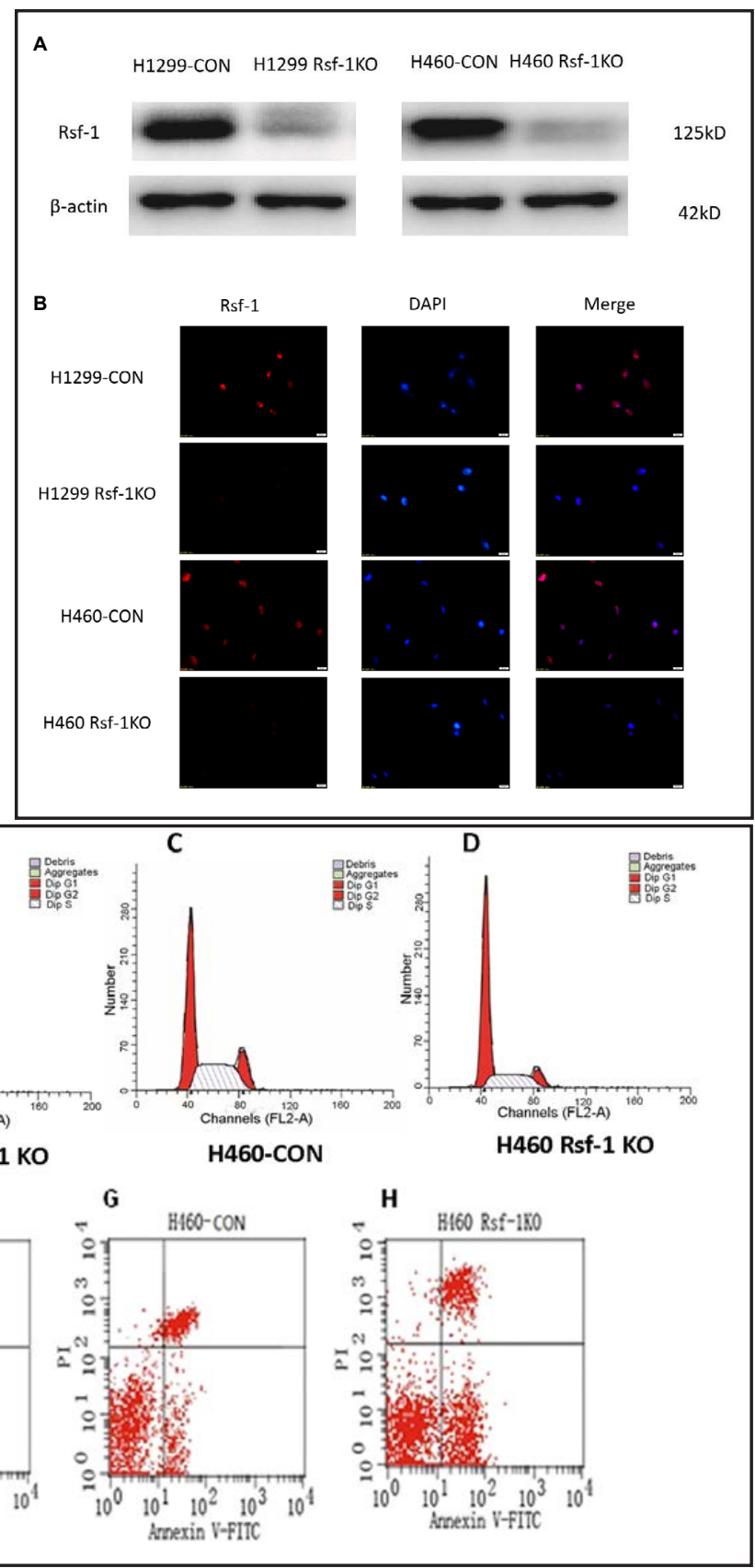

Fig. 3. Flow cytometry analysis of the impact of Rsf- 1 knockout on the progression of cell cycle and apoptosis. Panel A-D: impact of Rsf-1 knockout on the progression of cell cycle; panel A: the number of cells at different cell cycle phases in the control H1299 cells; panel B: the number of cells at different cell cycle phases in Rsf-1 knockout H1299 cells; panel C: the number of cells at different cell cycle phases in the control H460 cells; panel D: the number of cells at different cell cycle phases in Rsf-1 knockout H460 cells. Panel E-H: impact of Rsf-1 knockout on the cell apoptosis; panel D: the numbers of living cells and dead cells in control H1299 cells; panel E: the numbers of living and dead cells in H1299 cells with Rsf-1 knockout; panel F: the numbers of living cells and dead cells in the control H460 cells; panel H: the numbers of living cells and dead cells in H460 cells with Rsf-1 knockout. After Rsf-1 being knocked out, cells in G1 phase significantly increased while cells in S phase significantly decreased $(\mathrm{p}<0.05)$; the transit from $\mathrm{G} 1$ phase to $\mathrm{S}$ phase was significantly inhibited $(\mathrm{p}<0.05)$; and cell apoptosis was significantly increased $(\mathrm{p}<0.05)$, in both H1299 cells and H460 cells. 


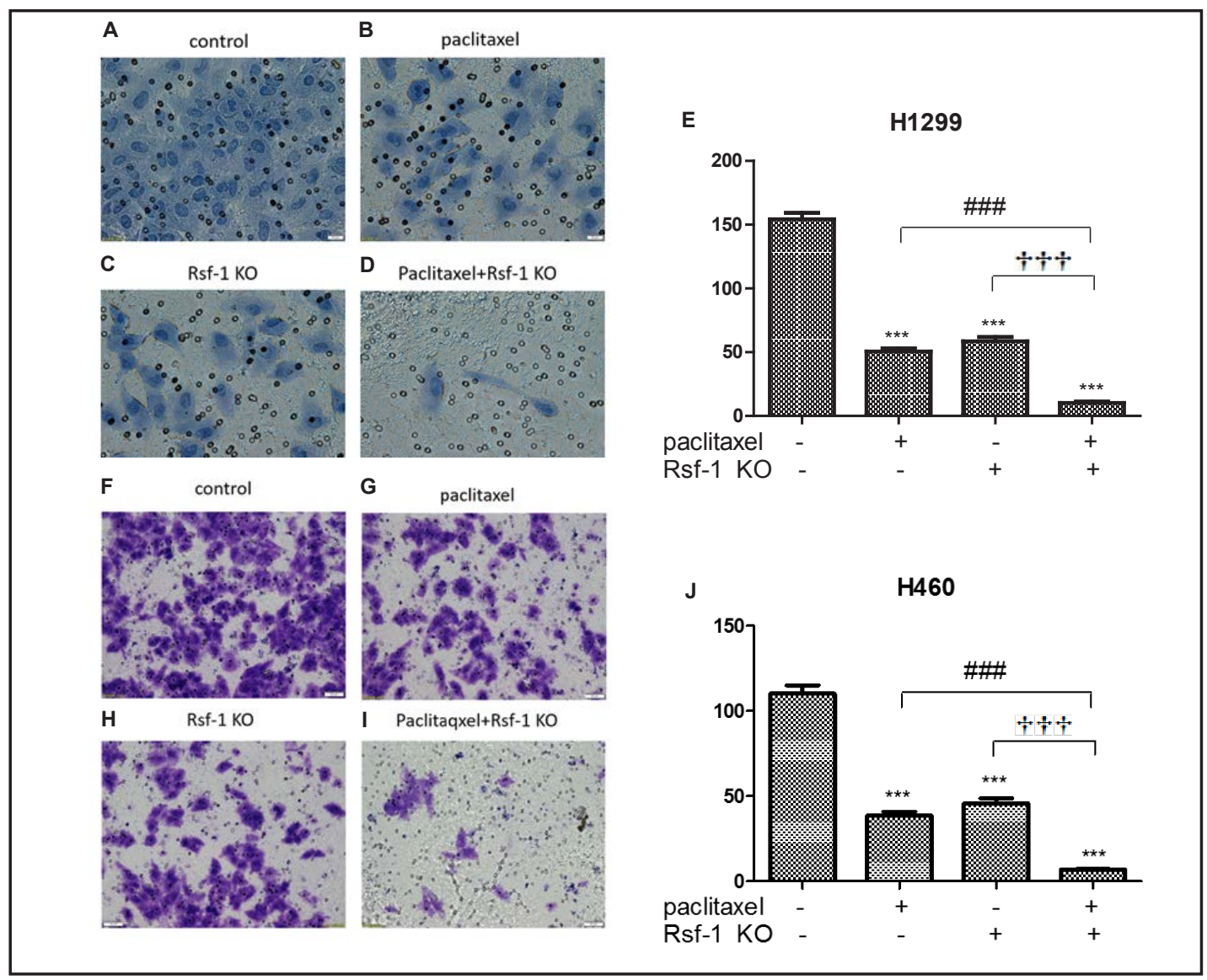

Fig. 4. Migration of H1299 and H460 cells after paclitaxel treatment and Rsf-1 knockout. A, control H1299 cells; B, H1299 cells treated with paclitaxel; C, Rsf-1 knockout H1299 cells; D, Rsf-1 knockout H1299 treated with paclitaxel; E; relative levels of cell migration in H1299 cell; F, control H460 cells; G, H460 cells treated with paclitaxel; H, Rsf-1 knockout H460 cells; I, Rsf-1 knockout H460 treated with paclitaxel; J, relative levels of cell migration in $\mathrm{H} 1299$ cell (*** $^{* *}$ significantly lower than the control cells, $\mathrm{p}<0.001$; \#\#\#: significantly different between cells treated with paclitaxel and the Rsf- 1 knockout cells treated with paclitaxel, $p<0.001$; †††: significantly different between the Rfs-1 knockout cells and the Rsf-1 knockout cells treated with paclitaxel, p<0.001).

$(p<0.001)$ decreased the cell migration in paclitaxel treated cells to even lower levels; and there was no significant $(p>0.05)$ difference in the cell migration ability between the cells treated with paclitaxel alone and the Rsf- 1 knockout cells without any other treatment (Fig. 4 A to J).

After the cells were treated with paclitaxel at $0.5 \mu \mathrm{g} / \mathrm{ml}, 1 \mu \mathrm{g} / \mathrm{ml}, 2 \mu \mathrm{g} / \mathrm{ml}$ and $4 \mu \mathrm{g} /$ $\mathrm{ml}$ for 48 hours, the inhibition of cell proliferation was significantly higher in H1299 Rsf$1 \mathrm{KO}$ and H460 Rsf-1 KO cells than the corresponding control cell (Fig. 5A and B). After cells were treated with $4 \mu \mathrm{g} / \mathrm{ml}$ paclitaxel for 24,48 and $72 \mathrm{~h}$, respectively, the inhibition of proliferation was also significantly higher in H1299 Rsf-1 KO and H460 Rsf-1 KO cells than the corresponding control cells at all time points, respectively (Fig. 5C and D). The inhibition of paclitaxel on cell proliferation increased as the time and dosage increased in all cell lines (Fig. 5A, B, C, D).

Caspase 3 and cleaved-caspase 3 (C-caspase3) expression

After H1299 CON, H1299 Rsf-1 KO, H460 CON and H460 Rsf-1 KO cells were treated with $4 \mu \mathrm{g} / \mathrm{ml}$ paclitaxel for $48 \mathrm{~h}$, the levels of caspase 3 and C-caspase 3 in the cells were detected with Western blotting (Fig. 6A, Fig. 7A,C). 


\section{Cellular Physiology Cell Physiol Biochem 2017;44:2322-2336

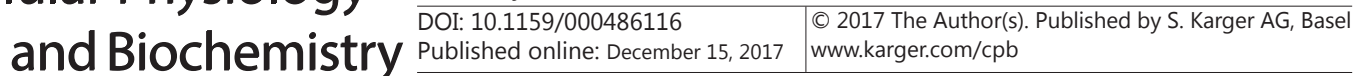

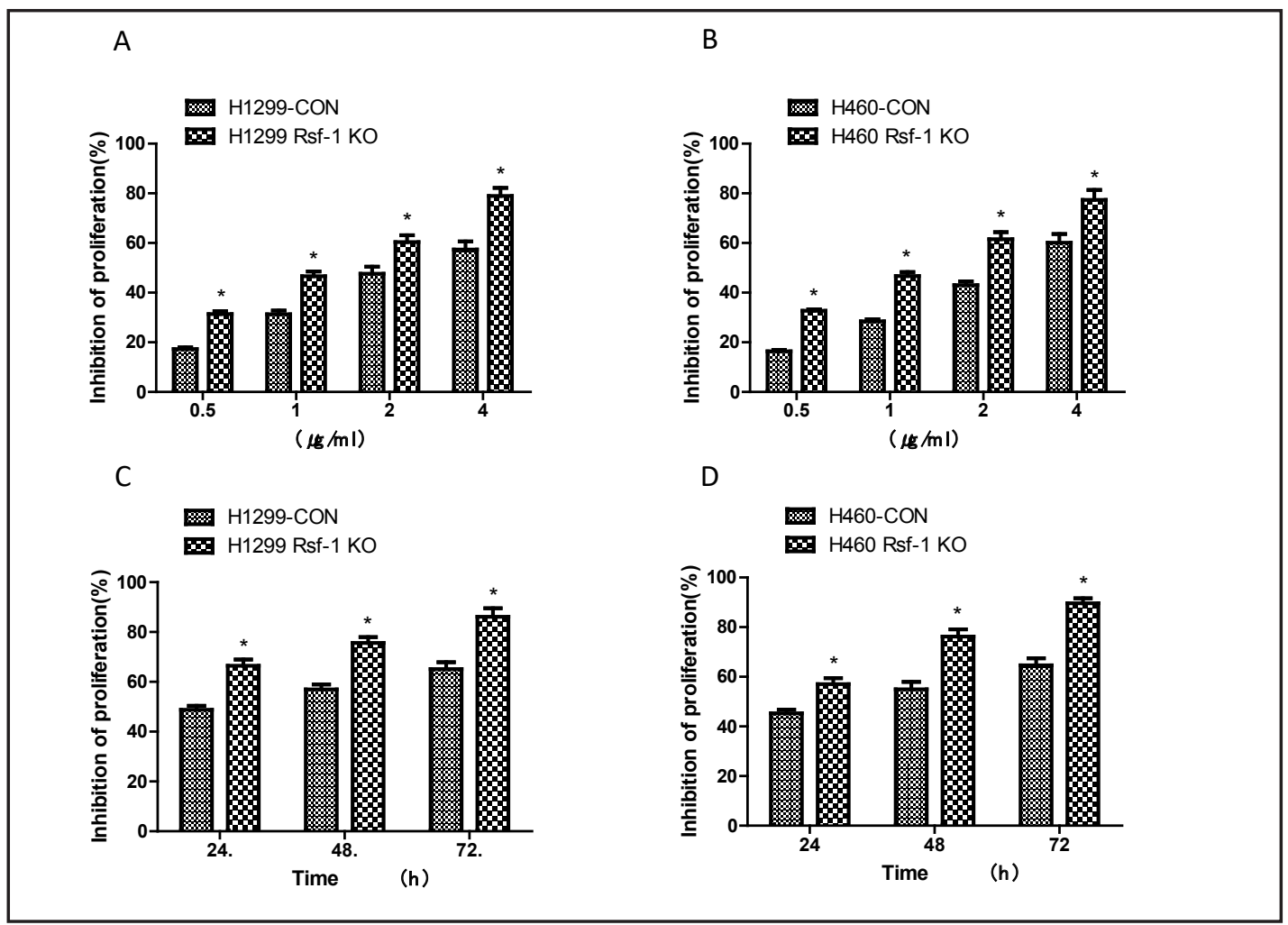

Fig. 5. Inhibition effect of paclitaxel on cell proliferation in vitro. Panel A: H1299 cells and H1299 cells with Rsf-1 knockout treated with different concentrations of paclitaxel; panel B: H460 cells and H460 cells with Rsf-1 knockout treated with different concentrations of paclitaxel; panel C: H1299 cells and H1299 cells with Rsf-1 knockout treated with $4 \mu \mathrm{g} / \mathrm{ml}$ of paclitaxel; panel D, H460 cells and H460 cells with Rsf-1 knockout treated with $4 \mu \mathrm{g} / \mathrm{ml}$ of paclitaxel; after cells were treated with paclitaxel at $0.5 \mu \mathrm{g} / \mathrm{ml}, 1 \mu \mathrm{g} / \mathrm{ml}$, $2 \mu \mathrm{g} / \mathrm{ml}$ and $4 \mu \mathrm{g} / \mathrm{ml}$ for $48 \mathrm{hours}$, or $4 \mu \mathrm{g} / \mathrm{ml}$ paclitaxel for $24 \mathrm{~h}, 48 \mathrm{~h}$ and $72 \mathrm{~h}$, the inhibition of proliferation was tested with CCK8 test (*: $\mathrm{p}<0.05)$.

The levels of caspase 3 protein were significantly higher in both H460 Rsf-1 KO and H1299 Rsf-1 KO cells than the corresponding control cells (Fig. 6B, C). The levels of caspase3 protein were significantly higher in $\mathrm{H} 460$ and H1299 cells treated with paclitaxel than the corresponding untreated cells (Fig. 6B, C). The level of caspase 3 protein significantly increased to an even higher level in H460 Rsf-1 KO cells treated with paclitaxel compared with H460 cells treated with paclitaxel and H460 Rsf-1 KO cells, respectively (Fig. 6C). The level of caspase3 protein significantly increased to an even higher level in H1299 Rsf-1 KO cells treated with paclitaxel compared with H1299 cells treated with paclitaxel and H1299 Rsf-1 KO cells, respectively (Fig. 6B).

The level of C-caspase 3 protein was significantly ( $p<0.05$ ) higher in both H460 Rsf-1 KO and H1299 Rsf-1 KO cells than the corresponding control cells (Fig. 7A to D). The level of C-caspase 3 protein was significantly ( $p<0.05)$ higher both $\mathrm{H} 460$ and H1299 cells treated with paclitaxel than the corresponding control cells (Fig. 7A to D). The level of C-caspase3 protein significantly $(\mathrm{p}<0.05)$ increased to an even higher level in H1299 Rsf-1 KO cells treated with paclitaxel compared with H1299 cells treated with paclitaxel and H1299 Rsf$1 \mathrm{KO}$ cells, respectively (Fig. 7A, B). The level of C-caspase3 protein significantly $(p<0.05)$ increased to an even higher level in H460 Rsf-1 KO cells treated with paclitaxel compared with H460 cells treated with paclitaxel and H460 Rsf-1 KO cells, respectively (Fig. 7C, D). 
Fig. 6. Expression level of caspase 3 in the cells treated with paclitaxel. Expression of caspase3 was detected after H1299 CON, H1299 Rsf-1 KO, H460 CON and H460 Rsf-1 KO cells were treated with $4 \mu \mathrm{g} / \mathrm{ml}$ paclitaxel for 48 . Panel A: expression of caspase 3 detected with Western blotting; panel B: relatively quantitative level of caspase3 in H1299 cells; panel C: relatively quantitative level of caspase 3 in $\mathrm{H} 460$ cell; 1 ) control cells without paclitaxel treatment; 2) control cells treated with paclitaxel; 3) Rsf-1 knocked out cells without paclitaxel treatment; 4) Rsf-1 knocked out cells treated with paclitaxel. GAPDH was used as an internal control (*: $\mathrm{p}<0.05$; \#: $\mathrm{p}<0.05 ; \uparrow: \mathrm{p}<0.05)$.

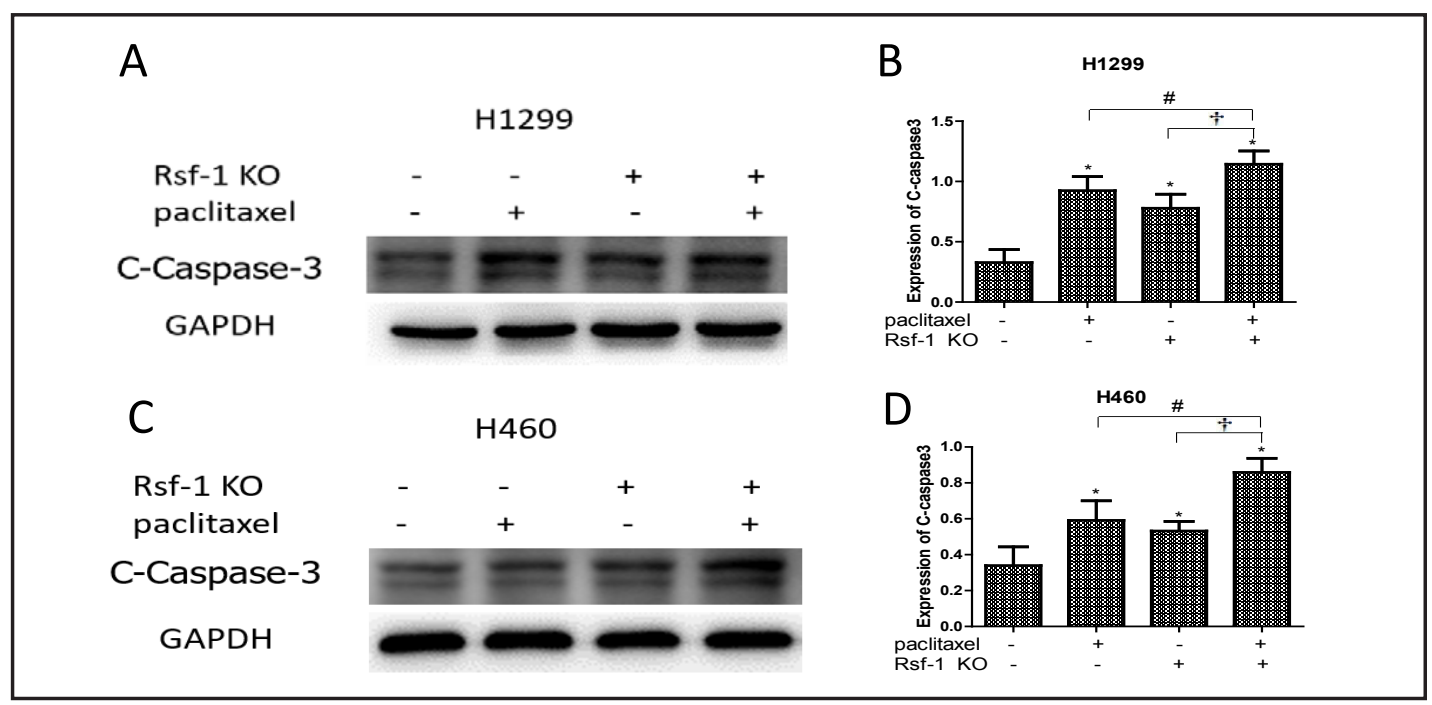

Fig. 7. Effects of paclitaxel on the level of C-caspase 3 in cells. Cells were treated with $4 \mu \mathrm{g} / \mathrm{ml}$ of paclitaxel for $48 \mathrm{~h}$, and the level of C-caspase 3 was tested with Western blotting using GAPDH as internal standard. A, Western blot of H1229 and H1299 Ref-1 KO cells; B, relative level of C-caspase 3 in H1229 and H1299 Rsf-1 KO cells; C, Western blot of H460 and H460 Ref-1 KO cells; D, relative level of C-caspase 3 in H460 and H460 Rsf-1 KO cells; E, Western blot of A549 and A549 Ref-1 KO cells; F, relative level of C-caspase 3 in A549 and A549 Rsf-1 KO cells; G, Western blot of SPC and SPC Ref-1 KO cells; F, relative level of C-caspase 3 in SPC and SPC Rsf-1 KO cells (*: compared to the control, P<0.05; \#: comparison between cells treated with paclitaxel alone with the Resf- 1 knockdown cells treated with paclitaxel, $p<0.05$; $\dagger$ : comparison between Rsf-1 knockdown cells with the Resf- 1 knockdown cells treated with paclitaxel, $\mathrm{p}<0.05$ ).

Effect of paclitaxel on tumor size, tumor weight and body weight in the mice with $\mathrm{H} 460$ cell or H460 Rsf-1 KO cell xenograft

From the fifteenth to the thirtieth day after the tumor cells were implanted into the nude mice, the tumors grew significantly $(\mathrm{p}<0.05)$ faster in the mice with H460 cell xenograft 

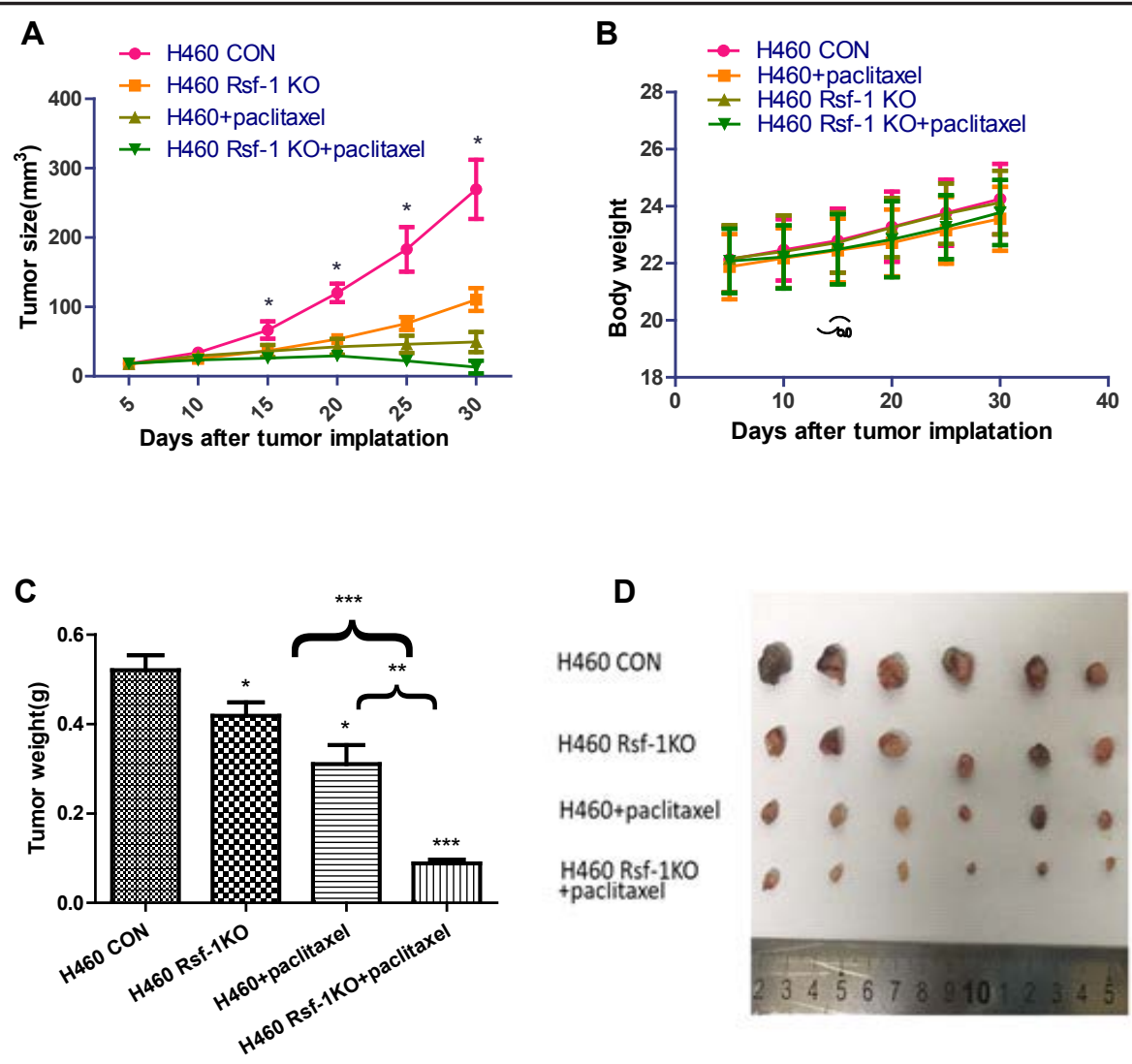

Fig. 8. Effect of paclitaxel on tumor size, tumor weight and body weight in the mice with H460 cell or H460 Rsf-1 KO cell xenograft. Panel A: growth curve of xenograft tumors; panel B: time course of the body weight of the animals; panel C: tumor weight; panel D: xenograft tumors. *: significant differences as compared to H460 control cells ( $\mathrm{p}<0.05)$; ${ }^{* *}$ : significant difference between $\mathrm{H} 460$ cells treated with paclitaxel and H460 Rsf-1KO cells treated with paclitaxel $(\mathrm{p}<0.01)$; ${ }^{* *}$ : significant difference between H460 Rsf-1KO cells and H460 Rsf-1KO cells treated with paclitaxel $(\mathrm{p}<0.001)$.

than in H460 cell xenograft mice treated with paclitaxel, H460 Rsf-1 KO cell xenograft mice, and H460 Rsf-1 KO cell xenograft mice treated with paclitaxel (Fig. 8A). On the thirtieth day after implanting tumor cells, the tumor volumes were significantly $(\mathrm{p}<0.05)$ larger in the mice implanted with $\mathrm{H} 460$ cells $\left(269.4 \pm 42.6 \mathrm{~mm}^{3}\right)$ than in $\mathrm{H} 460$ cell xenograft mice treated with paclitaxel $\left(49.4 \pm 14.5 \mathrm{~mm}^{3}\right)$, H460 Rsf-1 KO cell xenograft mice $\left(110.6 \pm 16.6 \mathrm{~mm}^{3}\right)$, and H460 Rsf-1 KO cell xenograft mice treated with paclitaxel $\left(13.0 \pm 9.2 \mathrm{~mm}^{3}\right)$ (Fig. 8A). During the test period, the body weights increased at a similar rate across all animal groups. The average body weight was $24.2 \pm 1.2 \mathrm{~g}$ for the mice implanted with $\mathrm{H} 460$ cells, $24.1 \pm 1.1 \mathrm{~g}$ for H460 Rsf-1 KO cell xenograft mice, $23.6 \pm 1.1 \mathrm{~g}$ for H460 cell xenograft mice treated with paclitaxel, and $23.8 \pm 1.1 \mathrm{~g}$ for H460 Rsf-1 KO cell xenograft mice treated with paclitaxel on the thirtieth day after tumor cell implantation ( $p>0.05$ ) (Fig. 8B). Thirty days after tumor cell implantation, the tumor weight was significantly lower in $\mathrm{H} 460$ cell xenograft mice treated with paclitaxel $(0.31 \pm 0.10 \mathrm{~g}, \mathrm{p}<0.05)$, H460 Rsf- 1 KO cell xenograft mice $(0.42 \pm$ $0.07 \mathrm{~g}, \mathrm{p}<0.05)$, and H460 Rsf-1 KO cell xenograft mice treated with paclitaxel $(0.09 \pm 0.02 \mathrm{~g}$, $\mathrm{p}<0.001)$ than the mice implanted with H460 cells $(0.52 \pm 0.08 \mathrm{~g})$, where H460 Rsf- 1 KO cell xenograft mice treated with paclitaxel demonstrated the greatest decrease (Fig. 8C, D). The decrease in the tumor weight in H460 Rsf-1 KO cell xenograft mice treated with paclitaxel was also significant $(\mathrm{p}<0.01)$ compared to $\mathrm{H} 460$ cell xenograft mice treated with paclitaxel and H460 Rsf-1 KO cell xenograft mice (Fig. 8C). 


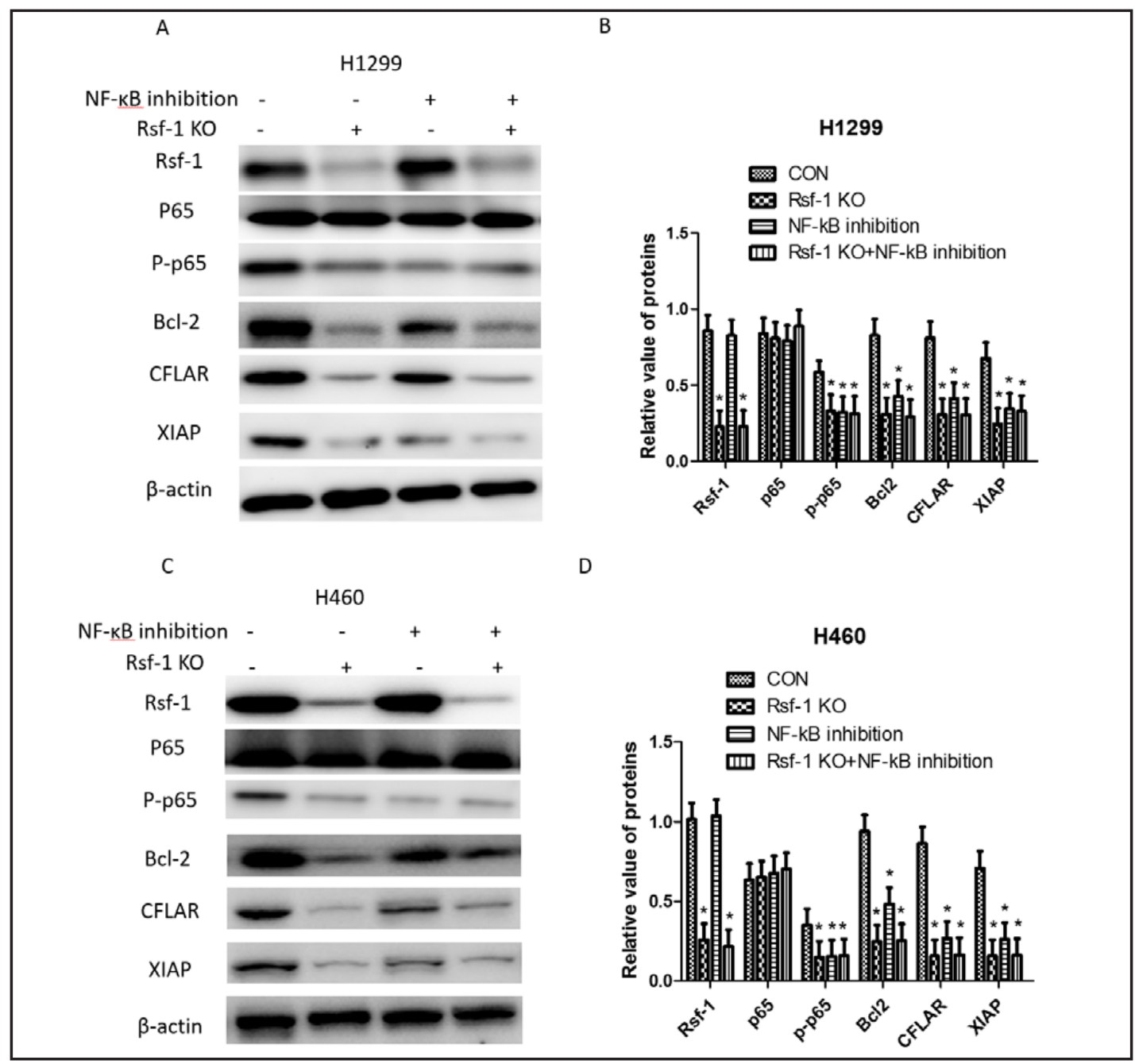

Fig. 9. Protein levels of the NF- $\kappa B$ pathway genes in $\mathrm{H} 1299$ and $\mathrm{H} 460$ cells. Both the control cells and Rsf-1 knockout cells were treated with NF- $\kappa$ B inhibitor. Protein levels of the NF- $\kappa B$ pathway genes were detected with Western blotting using $\beta$-actin as an internal standard. Panel A: proteins detected in H1299 cells with Western blotting; panel B: relative levels of the proteins detected in H1299 cells; panel C: proteins detected in H460 cells with Western blotting; panel D: relative levels of proteins detected in H460 cells (*: significant difference as compared to the control cells, $\mathrm{p}<0.05$ ).

\section{Protein expression of the genes involved in NF- $\kappa B$ pathway}

Rsf-1 knockout significantly decreased the levels of Rsf-1 protein in both H1299 and H460 cells (Fig. 9A to D, Fig. 10A to D). The protein expression levels of p-P65, BcL2, CFLAR, and XIAP were significantly $(\mathrm{p}<0.05)$ decreased after Rsf- 1 knockout, inhibition by NF- $\kappa \mathrm{B}$ pathway inhibitor, and Rsf-1 knockout plus NF- $\mathrm{BB}$ inhibition in $\mathrm{H} 1299$ and H460 cells (Fig. 9A to D). NF- $\kappa B$ inhibitor did not change the protein level of Rsf- 1 in H1299 cells or H460 cells (Fig. 9A to D). The level of p65 was not altered by Rsf-1 knockout, NF- $\kappa B$ inhibition, hSNF2H knockout, Rsf-1/hSNF2H double knockout, and Rsf-1 knockout plus NF- $\mathrm{BB}$ inhibition in H1299 cells or H460 cells ( $p>0.05$ ) (Fig. 9A to D, Fig.10A to D). There were no differences in the protein levels of Rsf-1 after hSNF2H was knocked down in H1299 cells (Fig. 10A, B) or H460 cells (Fig. 10C, D). Rsf-1 knockout alone and hSNF2H knockout alone significantly decreased the level of p-p65 in H1299 cells (Fig. 10A, B) or H460 cells (Fig. 10C, D) (p<0.05). Knocking out Rsf-1 from hSNF2H knockout cells further decreased the level of p-p65 down to the same as in Rsf-1 knockout H1299 cells (Fig. 10A, B) and Rsf-1 knockout H460 cells (Fig. 10C, D) $(\mathrm{p}<0.05)$. 


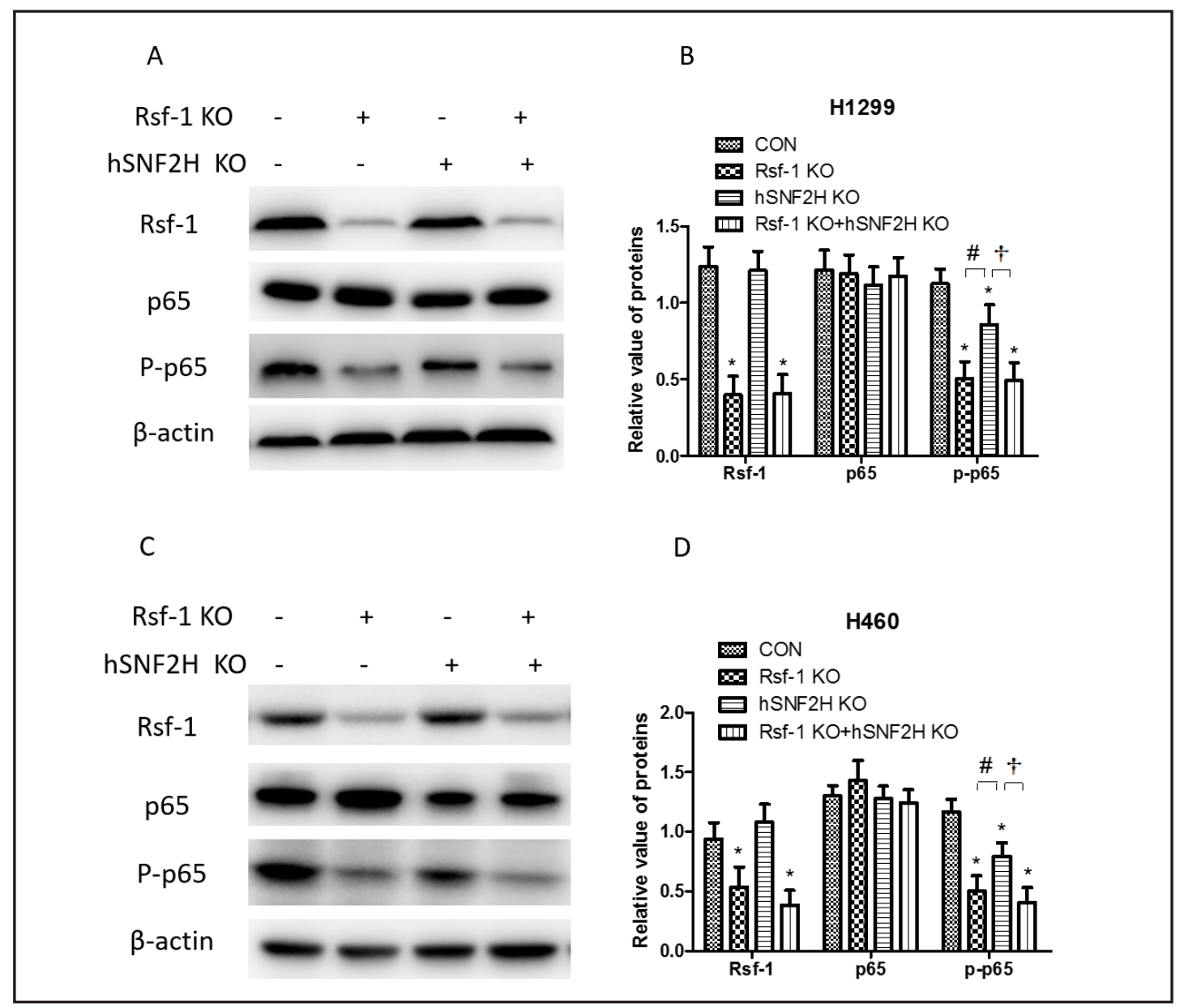

Fig. 10. Protein levels of p65 and p-p65 in H1299 cells and H460 cells. With Rsf-1 and hSNF2H single knockout and double knockout from the cells, the protein levels of p65 and p-p65 were tested with Western blotting using $\beta$-actin as an internal standard. A, Western blot of H1299 cells; B, relative levels of P65 and p-p65 in H1299 cells; C, Western blot of H460 cells; D, relative levels of P65 and p-p65 in H460 cells (*: significantly lower as compared to control, $\mathrm{p}<0.05$; \#: significantly higher in hSNF2H KO cells than Rsf- $1 \mathrm{KO}$ cells, $\mathrm{p}<0.05$; $\dagger$ : significantly higher in hSNF2H KO cells than Rsf-1 and hSNF2H double knockout cells, $\mathrm{p}<0.05$ ).

\section{Discussion}

In this study, it was found that Rsf-1 knockout and paclitaxel treatment increased apoptosis and decreased cell proliferation in cultured NSCLC cells, and inhibited the growth of tumors in the nude mice. Rsf-1 knockout enhanced the inhibition effect of paclitaxel on NSCLC in vivo and in vitro to even higher levels. Both helenalin inhibition of NF- $\kappa B$ pathway and the strategies of Rsf-1 and hSNF2H knockout demonstrated that Rsf-1 influenced the sensitivity of NSCLC to paclitaxel via regulation of the NF- $\kappa B$ pathway.

\section{Rsf-1 influences the sensitivity of non-small cell lung cancer to paclitaxel}

RSF1, a histone-binding protein, plays an important role in chromatin remodeling and transcriptional regulation [9]. RSF1 gene is overexpressed and increases proliferation in various cancers, including ovarian [7], breast [10], bladder [11], esophageal [12], colon [14], and head and neck cancers [15], and correlates with poor prognosis [16]. In this study, we 
also observed that Rsf-1 knockout mediated arrest of cells at G1 phase, elevated caspase 3 and C-caspase 3 protein levels and cell apoptosis, reduced cell migration ability and cell proliferation in H460 and H1299 cells, and decreased the volume, weight, and the growth of tumors in $\mathrm{H} 460$ cell xenograft mice. These results confirm that Rsf- 1 contributes to malignant cell growth, invasion and poor overall survival in NSCLC [20, 23]. Rsf-1 knockout increased the inhibition effect of cell proliferation, the reduction of cell migration ability and the augmentation of caspase 3 and C-caspase 3 protein levels by paclitaxel in $\mathrm{H} 460$ and H1299 cells. Rsf-1 knockout further decreased the volume, weight, and the growth of tumors by paclitaxel without influencing the body weight in $\mathrm{H} 460$ cell xenograft mice. These observations indicate that Rsf-1 knockout increases the sensitivity of NSCLC to paclitaxel, which is in agreement with the enhanced paclitaxel resistance by Rsf-1 in ovarian cancer $[17,18]$ and nasopharyngeal carcinoma [19]. It is proposed that an inhibitor of Rsf-1 would reverse Rsf-1 enhanced paclitaxel resistance, and if used in combination with paclitaxel, might be able to potentiate the chemotherapeutic efficacy of paclitaxel to treat NSCLC, just as observed in the YAP overexpression colon cancer HCT-8 cells treated by verteporfin [24].

\section{NF-kB pathway is activated by Rsf-1}

It is well defined that Rsf- 1 contributes to chemoresistance in many cancers through activation of the NF- $\kappa B$ pathway $[18,19,23,25]$. Rsf-1 knockout decreased the protein levels of p-P65, BcL2, CFLAR, and XIAP in H1299 and H460 cells, confirming that Rsf-1 regulates the activation of NF- $\kappa \mathrm{B}$ and the expression of the genes downstream of NF- $\kappa \mathrm{B}$ complex [23, 25]. Inhibition of the NF- $\kappa B$ pathway by helenalin decreased the protein levels of $\mathrm{p}-\mathrm{P} 65$, BcL2, CFLAR, and XIAP in these cells without altering Rsf-1 protein levels, suggesting that Rsf-1 acts on the NF- $\kappa B$ pathway at a point no further downstream from the site of helenalin inhibition. In the classical (or canonical) pathway, NF- $\mathrm{KB}$, composed of a p50 and a p65 subunit, is retained in an inactive cytoplasmic complex by binding to a third, inhibitory subunit IKB. Activation of IKK triggers the phosphorylation and proteolytic degradation of the IкB subunit, which then releases active NF- $\kappa B$ (p-P65) from the cytoplasmic complex. The activated factor then translocates to the nucleus, where it stimulates the transcription of its target genes. Helenalin, the sesquiterpene lactone parthenolide, was reported to

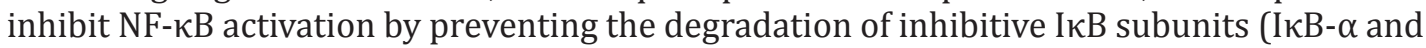
IкB- $\beta$ ) [26], or selectively alkylating the p65 subunit of the transcripition factor, thereby inhibiting its DNA binding [27]. The unaltered level of $\mathrm{p} 65$ and the reduced level of p-P65 by helenalin inhibition indicated that helenalin inhibited NF- $\kappa B$ activation through reducing the phosphorylation of p65 in H1299 and H460 cells.

hSNF2H and Rsf-1 were co-upregulated in several human cancers, such as ovarian cancer [8] and glioma [25]. hSNF2H translocates into nuclei and interacts with Rsf-1 to form a chromatin remodeling complex (Rsf complex) that regulates gene expression and participates in several biological processes [8]. Formation of the Rsf-1/hSNF2H complex, as coactivators [18], is required for Rsf-1 overexpression to enhance paclitaxel resistance in ovarian cancer [17] and glioma [25] through regulating NF- $\kappa B[18,25]$. In the present study, hSNF2H knockout decreased the protein levels of NF- $\mathrm{kB}$ p-P65 without altering the protein levels of Rsf- 1 or p65, and Rsf- 1 and hSNF2H double knockout led to an even more decrease in the levels of NF-kB p-P65 in H1299 Rsf-1 KO cells and H460 Rsf-1 KO cells. These results support that Rsf-1 interacts with hSNF2H to activate the NF- $\mathrm{BB}$ pathway in NSCLCs.

The NF- $\mathrm{BB}$ pathway is found to cross talk with other signal transduction pathways through transcription factors, such as STAT3, p53 and AKT [28]. It is expected that chemicals, such as CB-PIC [29] and SI113 [30], which act on STAT3 [29], AKT [29], and p53 [30], may further influence the activation of NF- $\kappa \mathrm{B}$ and its downstream genes, and compensate for the decreased paclitaxel sensitivity by Rsf- 1 in NSCLCs. The cross talk between YAP and NF$\kappa B[31]$ suggests that verteporfin should have the potential to reverse paclitaxel enhanced resistance in NSCLCS [24]. 


\section{Cellular Physiology Cell Physiol Biochem 2017;44:2322-2336 \begin{tabular}{ll|l} 
DOI: 10.1159/000486116 & $\begin{array}{l}\text { O } 2017 \text { The Author(s). Published by S. Karger AG, Basel } \\
\text { www.karger.com/cpb }\end{array}$ \\
\hline and Biochemistry & Published online: December 15, 2017
\end{tabular} \\ Chen et al.: Rsf-1 Influences the Sensitivity of Non-Small Cell Lung Cancer to Paclitaxel Drug}

\section{Conclusion}

It was concluded that Rsf-1 was highly expressed in H1299 and H460 cells. Paclitaxel inhibited the invasion and growth of NSCLC by reducing migration ability, increasing cell apoptosis, and reducing cell proliferation. Rsf-1 knockout mediated arrest of cells at G1 phase, elevated cell apoptosis, reduced cell migration ability and reduced cell proliferation in H460 and H1299 cells, and decreased the volume, weight, and the growth of tumors in H460 cell xenograft mice. Rsf-1 knockout also enhanced the anticancer effects of paclitaxel on NSCLC both in vitro and in vivo. Rsf-1 influenced the sensitivity of NSCLCs to paclitaxel by interacting with hSNF2H and regulating the activation of NF- $\kappa \mathrm{B}$ and the expression of its downstream genes.

\section{Acknowledgements}

This study was funded by National Natural Science Foundation of China (No. 81672964), Natural Science Foundation of Liaoning Province (201602838) and Education department of Liaoning province key laboratory fund project (LS201608).

\section{Disclosure Statement}

The authors declare that they have no competing interests.

\section{References}

1 Molina JR, Yang P, Cassivi SD, Schild SE, Adjei AA: Non-small cell lung cancer: epidemiology, risk factors, treatment, and survivorship. Mayo Clin Proc 2008;83:584-594.

-2 Zhou C: Lung cancer molecular epidemiology in China: recent trends. Transl lung cancer Res 2014;3:270279.

3 Reck M, Heigener DF, Mok T, Soria J-C, Rabe KF, Jemal A, Bray F, Center MM, Ferlay J, Ward E, Forman D, Lozano R, Naghavi M, Foreman K, Al. E, Devesa SS, Bray F, Vizcaino AP, Parkin DM, Morgensztern D, Ng SH, Gao F, Govindan R, Schiller JH, Harrington D, Belani CP: Management of non-small-cell lung cancer: recent developments. Lancet (London, England) 2013;382:709-719.

4 Yamori T, Sato S, Chikazawa H, Kadota T: Anti-tumor efficacy of paclitaxel against human lung cancer xenografts. Jpn J Cancer Res 1997;88:1205-1210.

5 Priyadarshini K, Keerthi AU: Paclitaxel Against Cancer: A Short Review. Med chem 2012;2:139-141.

6 Le XF, Bast RC: Src family kinases and paclitaxel sensitivity. Cancer Biol Ther 2011;12:260-269.

7 Shih I, Sheu JJ, Santillan A, Nakayama K, Yen MJ, Bristow RE, Vang R, Parmigiani G, Kurman RJ, Trope CG, Davidson B, Wang TL: Amplification of a chromatin remodeling gene, Rsf-1/HBXAP, in ovarian carcinoma. Proc Natl Acad Sci USA 2005;102:14004-14009.

-8 Sheu JJ-C, Jung HC, Yildiz Isil, Tsai FJ, Shaul Y, Wang TL, Shih IM: The roles of human sucrose nonfermenting protein 2 homologue in the tumor-promoting functions of Rsf-1 Cancer Res 2008;68:4050-4057.

-9 Sheu JJ-C, Guan B, Choi J-H, Lin A, Lee C-H, Hsiao Y-T, Wang T-L, Tsai F-J, Shih I-M : Rsf-1, a chromatin remodeling protein, induces DNA damage and promotes genomic instability. J Biol Chem 2010;285:3826038269.

10 Mao TL, Hsu CY, Yen MJ, Gilks B, Sheu JJ, Gabrielson E, Vang R, Cope L, Kurman RJ, Wang TL, Shih IM : Expression of Rsf-1, a chromatin-remodeling gene, in ovarian and breast carcinoma. Hum Pathol 2006;37:1169-1175.

11 Chen T, Huang S, Huang H, Wei Y, Li C: Rsf-1/HBXAP overexpression is associated with disease-specific survival of patients with gallbladder carcinoma. APMIS 2011;119:808-814. 


\section{Cellular Physiology Cell Physiol Biochem 2017;44:2322-2336 \begin{tabular}{l|l|l} 
and Biochemistry & $\begin{array}{l}\text { DOI: 10.1159/000486116 } \\
\text { Published online: December 15, } 2017\end{array}$ & $\begin{array}{l}\text { C) } 2017 \text { The Author(s). Published by S. Karger AG, Basel } \\
\text { www.karger.com/cpb }\end{array}$
\end{tabular}}

Chen et al.: Rsf-1 Influences the Sensitivity of Non-Small Cell Lung Cancer to Paclitaxel Drug

12 Fang F-M, Li C-F, Huang H-Y, Lai M-T, Chen C-M, Chiu I-W, Wang T-L, Tsai F-J, Shih I-M, Sheu JJ-C: Overexpression of a Chromatin Remodeling Factor, RSF-1/HBXAP, Correlates with Aggressive Oral Squamous Cell Carcinoma. Am J Pathol 2011;178:2407-2415.

13 Zhang X, Fu L, Xue D, Zhang X, Hao F, Xie L, He J, Gai J, Liu Y, Xu H, Li Q, Wang E: Overexpression of Rsf1 correlates with poor survival and promotes invasion in non-small cell lung cancer. Virchows Arch 2017;470:553-560.

14 Liu S, Dong Q, Wang E: Rsf-1 overexpression correlates with poor prognosis and cell proliferation in colon cancer. Tumor Biol 2012;33:1485-1491.

15 Tai H-C, Huang H-Y, Lee S-W, Lin C-Y, Sheu M-J, Chang S-L, Wu L-C, Shiue Y-L, Wu W-R, Lin C-M, Li C-F: Associations of Rsf-1 overexpression with poor therapeutic response and worse survival in patients with nasopharyngeal carcinoma. J Clin Pathol 2012;65:248-253.

16 Liang P-I, Wu L-C, Sheu JJ-C, Wu T-F, Shen K-H, Wang Y-H, Wu W-R, Shiue Y-L, Huang H-Y, Hsu H-P, Chen Y-H, Chen L-T, Li C-F, Liao AC: Rsf-1/HBXAP overexpression is independent of gene amplification and is associated with poor outcome in patients with urinary bladder urothelial carcinoma. J Clin Pathol 2012;65:802-807.

17 Choi JH, Sheu JJC, Guan B, Jinawath N, Markowski P, Wang TL, Shih IM: Functional analysis of 11q13.5 amplicon identifies Rsf-1 (HBXAP)as a gene involved in paclitaxel resistance in ovarian cancer. Cancer Res 2009;69:1407-1415.

18 Yang Y-IY, Ahn J-HA, Lee K-T, Shin I-MS, Choi J-H: RSF1 Is a Positive Regulator of NF- $\kappa B-I n d u c e d$ Gene Expression Required for Ovarian Cancer Chemoresistance. Cancer Res 2014;74:2258-2269.

19 Liu Y, Li GL, Liu C, Tang YT, Zhang S: RSF1 regulates the proliferation and paclitaxel resistance via modulating NF- $\mathrm{B}$ signaling pathway in nasopharyngeal carcinoma. J Cancer 2017;8:354-362.

20 Li Q Dong Q Wang E: Rsf-1 is overexpressed in non-small cell lung cancers and regulates cyclinD1 expression and ERK activity. Biochem Biophys Res Commun 2012;420:6-10.

-21 Mahmood T, Yang PC: Western blot: Technique, theory, and trouble shooting. N Am J Med Sci 2012;4:429434.

22 Jennette JC, Wick MR: Immunohistochemical Techniques; in Jennette JC (eds): Immunohistology in diagnostic pathology. Boca Raton, Florida,1989, pp 1-28.

23 Zhang X, Fu L, Xue D, Zhang X, Hao F, Xie L, He J, Gai J, Liu Y, Xu H, Li Q, Wang E: Overexpression of Rsf1 correlates with poor survival and promotes invasion in non-small cell lung cancer. Virchows Arch 2017;470:553-560.

24 Pan W, Wang Q Zhang Y, Zhang N, Qin J, Li W, Wang J, Wu F, Cao L, Xu G: Verteporfin can reverse the paclitaxel resistance induced by YAP over-expression in HCT-8/T cells without photoactivation through inhibiting YAP expression. Cell Physiol Biochem 2016;39:481-490.

25 Zhao XC, An P, Wu XY, Zhang LM, Long B, Tian Y, Chi XY, Tong DY: Overexpression of hSNF2H in glioma promotes cell proliferation, invasion, and chemoresistance through its interaction with Rsf-1. Tumour Biol 2016;37:7203-7212.

-26 Hehner SP, Heinrich M, Bork PM, Vogt M, Ratter F, Lehmann V, Schulze-Osthoff K, Dröge W, Schmitz ML:

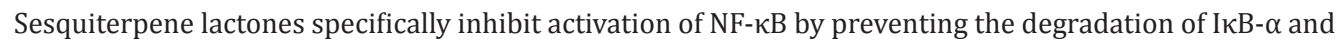
IкB- $\beta$. J Biol Chem 1998;273:1288-1297.

-27 Lyss G, Knorre A, Schmidt TJ, Pahl HL, Merfort I: The Anti-inflammatory Sesquiterpene Lactone Helenalin Inhibits the Transcription Factor NF-кB by Directly Targeting p65. J Biol Chem 1998;273:33508-33516.

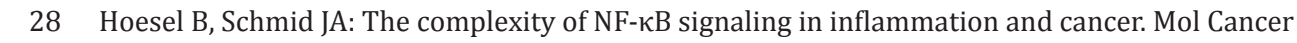
2013;12:86.

29 Yun M, Lee D, Park MN, Kim EO, Sohn EJ, Kwon BM, Kim SH: Cinnamaldehyde derivative (CB-PIC) sensitizes chemo-resistant cancer cells to drug-induced apoptosis via suppression of MDR1 and its upstream STAT3 and AKT signalling. Cell Physiol Biochem 2015;35:1821-1830.

30 D’Antona L, Amato R, Talarico C, Ortuso F, Menniti M, Dattilo V, Iuliano R, Gigliotti F, Artese A, Costa G, Schenone S, Musumeci F, Abbruzzese C, Botta L, Trapasso F, Alcaro S, Paggi MG, Perrotti N: SI113, a specific inhibitor of the Sgk1 kinase activity that counteracts cancer cell proliferation. Cell Physiol Biochem 2015;35:2006-2018.

-31 Gao Y, Yang Y, Yuan F, Huang J, Xu W, Mao B, Yuan Z, Bi W: TNF $\alpha$-YAP/p65-HK2 axis mediates breast cancer cell migration. Oncogenesis 2017; 6:e383. 